Report on Fusion Plasma Theory Grant

\title{
Theoretical Studies of Turbulence and Anomalous Transport in Toroidal Confinement Devices
}

\author{
P.W. Terry \\ Department of Physics \\ University of Wisconsin-Madison \\ 1150 University Avenue \\ Madison, Wisconsin 53706
}

Prepared for

THE U.S. DEPARTMENT OF ENERGY UNDER GRANT NO. DE-FG02-89ER53291

NOTICE: This report was prepared as an account of work sponsored by the United States Government. Neither the United States nor the Department of Energy, nor any of their employees, makes any warranty, express or implied, or assumes any legal liability or responsibility for the accuracy, completeness, or usefulness of any information, apparatus, product or process disclosed or represents that its use would not infringe privately owned rights. 


\begin{abstract}
The research performed under this grant has focused on key issues with respect to turbulence and transport in toroidal confinement devices. This work includes theoretical and computational studies of electron thermal confinement which have concentrated on the role of sheared poloidal flow in suppressing turbulence and transport, trapped ion convective cell turbulence and microtearing turbulenc $;$; analytical studies of anomalous particle transport and pinch mechanisms and comparison with experimental measurement; development of the theory of self-consistent radial transport of field-aligned momentum in the tokamak and RFP; and work on other topics (ion temperature gradient driven turbulence, RFP fluctuation theory, coherent structures). Progress and publications in these areas are summarized in this report.
\end{abstract}




\section{Introduction}

This report on the Fusion Plasma Theory DOE Grant Number DE-FG0289ER53291 at the University of Wisconsin covers work performed during the first year of the three year grant period beginning Sept. 15, 1991.

The research summarized in this report is devoted to the theoretical understanding of turbulence and anomalous transport in magnetic fusion devices. It covers a variety of topics ranging from basic properties of drift wave turbulence to properties of specific fluctuation models. The work is concerned with fluctuations in tokamaks. One topic, however, in addition to its bearing of tokamaks, is directly relevant to the RFP.

Work performed on the following topics is briefly discussed in the following sections: II. Self-consistent flow generation and flow suppressed turbulence, III. Dissipative trapped ion convective cell turbulence, IV. Drift wave frequency spectrum, and V. Anomalous ion heating. Section VI gives a short summary. A list of publications and fusion program activities supported by this grant is provided in Appendix A and Appendix $B$ lists the names of personnel engaged in research under this grant.

\section{Self-consistent now generation and flow suppressed turbulence [A.5,} A.8, A.12, A.15]

Initial analyses of the effect of shear flow on turbulent fluctuations and transport ${ }^{1,2}$ have been followed by a systematic study of turbulence suppression by differentially rotating flows and the generation of such flows by turbulent momentum transport. A hallmark of these studies has been the development of a self-consistent treatment, and attention to the role of flow curvature and the interplay of flow shear and magnetic shear as mediated by the nonlinear fluctuation structure. The use of a simple analytically tractable model based on dissipative trapped electron mode turbulence, and extensive computational work carried out by the Oak Ridge group, have led to the following conclusions.

1) Flow curvature (which in DIII-D is observed to be large in magnitude and localized in the region of fluctuation suppression ${ }^{3}$ ) is found to have a robust effect on linear stability. For dissipative trapped electron mode turbulence, positive curvature produces a potential well structure, thereby reducing the linear growth rate.

2) Turbulence suppression by shear flow can be obviated at finite amplitude by nonlinear fluctuation structure that is localized away from magnetic shear mediated dissipation. This effect is pronounced near low order rational surfaces and depends on the turbulence level. For strong turbulence, shear flow suppression is eliminated while for 
weak turbulence or strong flow shear, suppression effects are possible. An important conclusion of this work is that suppression studies based on linear stability analyses can be very misleading.

3) Both flow curvature and shear flow can be generated by turbulent momentum transport as described by the Reynold's stress. Curvature generation requires mode structure with radial propagation, typically furnished by diamagnetic effects, whereas shear requires radial propagation and radial asymmetry. The latter can arise as a consequence of geometry ${ }^{4}$, as occurs near a limiter, for example, or can be induced by a seed flow with shear.

4) The self-consistent treatment of saturated turbulence in the presence of turbulently generated flow shear and curvature yields solutions with a bifurcation-like transition. At low edge temperature, strong magnetic pumping is unfavorable for flow generation and the only stable solution is one with no flow and a large fluctuation level. At high edge temperature this solution becomes unstable and curvature and shear are spontaneously generated. The system transitions to a solution with either a steady state curvature or a steady state shear flow (or both) and a decreased fluctuation level. The set of simple model equations which yield this behavior indicate the possibility of an L-H transition process which is one step and does not involve an external (non-turbulent) mechanism such as orbit loss 5 .

III. Dissipative trapped ion convective cell turbulence [A.2, A.6, A.9, A.12, A.13, A.14, A.16]

Numerical investigation of dissipative trapped ion convective cell turbulence ${ }^{6}$ was initiated in the previous grant period and focused on the long wavelength regime relevant to observation of fluctuations in the tokamak core 7,8 . Prior study was restricted to the extreme long wavelength regime where the modes are unstable and the $E \times B$ nonlinearity dominates the transfer process. In the present grant period, the nonlinear transfer of energy and enstrophy was examined in intermediate and high wavenumber regimes where the polarization drift nonlinearity also plays a role. As the wavenumber increases $\left(k \rho_{s} \gtrsim \delta=\right)$, the $E \times B$ nonlinearity continues to transfer energy nonlocally in $k$ space to shorter wavelengths, but the polarization drift nonlinearity, with a dual transfer of energy to low $\mathrm{k}$ and enstrophy to high $k$, begins to compete and eventually dominates for $k \rho_{\mathrm{s}} \gg \delta$. Consistent with "lis behavior, the enstrophy generation rate at low $\mathrm{k}$ is comparable to the nonlinear interaction rate, while for high $\mathrm{k}$ it becomes smaller. Overall transfer in the 
regime where the two nonlinearities are comparable remains nonlocal, but is largely isotropic. A novel and potentially important result of these studies is the observation of a large shift of the frequency spectrum peak in this regime. This shift results from three wave interactions coupling the two nonlinearities in the turbulent response function.

The wavenumber spectrum associated with the nonlocal transfer of the $E \times B$ nonlinearity was also calculated from a two-point theory [A.12]. Energy conservation requires that the nonlocal transfer act as a source at short scale and results in a flattening of the spectrum as observed in the computations.

\section{Frequency spectrum of drift wave turbulence [A.3, A.10]}

The frequency spectrum of drift wave turbulence was examined in weak and strong turbulence regimes. Given its potential importance in transport and stability, the nature and physical origin of shifts of the frequency spectrum peak (associated with both the response function and otherwise) were a principal focus of the study. In weak turbulence theory, a spectrum shift was found which was attributable to the influence of the turbulently fluctuating density gradient on the drift frequency. For the hot ion $\left(T_{i} \geq T_{e}\right)$ dispersion curve, this produces a net frequency upshift, thereby reducing the amount of free energy available to the turbulence. For $T_{i}<T_{e}$, a downshift occurs. For strong turbulence, the Hasegawa-Mima model was examined using the DIA closure. For short wavelength, the frequency spectrum is given by the Fourier transform of the response function ${ }^{9}$. For the Hasegawa-Mima equation, the spectrum has a turbulent broadening, but no shift. For long wavelengths (below a long wavelength peak), the spectrum is governed by both the response function and the driving of low $\mathrm{k}$ fluctuations by shorter wavelength modes. The high $\mathrm{k}$ modes represent a broadband "source" which both shifts and broadens the spectrum of low $\mathrm{k}$ modes.

Numerical studies of frequency spectrum phenomenology have also been initiated. Preliminary results from numerical solution of the Terry-Horton equation show shifts that systematically increase with fluctuation level (as is characteristic of the width ${ }^{10}$ ). In a variety of circumstances, complicated spectra with multiple features and peaks are observed. Understanding these spectra will be a primary objective of future studies.

\section{Anomalous ion heating [A.4, A.11]}


Ion heating resulting from a cascade driven by unstable tearing modes was studied analytically in an effort to understand observations of anomalous ion heating in the RFPll. This work indicates that anomalous ion heating is not viscous in nature, as previously thought, but results from ion cyclotron resonant interactions with short scale fluctuations excited in the turbulent cascade. In the calculation performed, energy through-put in the cascade is related to the inverse helicity cascade required to maintain the reversed toroidal field against resistive decay. The cascaded energy is damped on the ions and electrons via ion cyclotron and electron Landau resonances. Electron and ion heating rate predictions are given. This picture is consistent with experimental observations that show both ion heating and reversed toroidal field generation correlation with the increased magnetic fluctuation activity and broadened spectra accompanying flux jumps.

\section{Summary}

As discussed in the preceding text, a range of topics in turbulence and ancmalous transport have been studied during the past year. The list of published papers and conference presentations in Appendix A attest that considerable progress has been made. In particular, 1) knowledge of the role of differentially rotating flow on plasma turbulence has been extended to include the effect of curvature and nonlinear fluctuation structure (and its interaction with magnetic shear). A self-consistent steady state with bifurcations resulting from turbulently generated flow has also been found and studied. 2) The nonlinear transfer of dissipative trapped ion convective turbulence has been examined over a broad spectral range incorporating the transfer of both the $\mathrm{E} \times \mathrm{B}$ and polarization drift nonlinearities and transfer and spectrum properties have been determined. 3) An initial study of frequency spectrum phenomenology in drift wave turbulence has been completed in order to determine the nature of nonlinear frequency shifts, and 4) anomalous ion heating rates have been calculated from ion cyclotron absorption of broadband dynamo related tearing mode activity in the RFP. 


\section{References}

1. H. Biglari, P.H. Diamond, and P.W. Terry, "Influence of Sheared Poloidal Rotation on Edge Turbulence", Phys. Fluids B2, 1 (1990).

2. Y.B. Kim, P.H. Diamond, H. Biglari, and P.W. Terry, "Theory of ResistivityGradient-Driven Turbulence in a Differentially Rotating Plasma", Phys. Fluids B 2, 2143 (1990).

3. R.J. Groebner, K.H. Burrell, and R.P. Seraydian, Phys. Rev. Lett. 64, 3015 (1990).

4. P.H. Diamond and Y.B. Kim, Phys. Fluids B 3, 1626 (1991).

5. K.C. Shaing, G.S. Lee, B.A. Carreras, W.A. Houlberg, and E.J. Crume, Jr., in Plasma Physics and Controlled Nuclear Fusion Reseash 1988, (IAEA, Vienna, 1989) Vol. 2, p. 13.

6. P.H. Diamond and H. Biglari, Phys. Rev. Lett. 65, 2865 (1990).

7. R.J. Fonck, S.F. Paul, D.R. Roberts, Y.J. Kim, N. Bretz, D. Johnson, R. Nazikian, and G. Taylor, 18th European Conference of Controlled Fusion and Plasma Physics (European Physical Society, Berlin, Vol. 15C, Part I, 1991) p. I269.

8. P. Cripwell and A.E. Costley, 18th European Conference of Controlled Fusion and Plasma Physics (European Physical Society, Berlin, Vol. 15C, Part I, 1991) p. I-17.

9 . R.H. Kraichnan, Phys. Rev. 109, 1407 (1958).

10. P.W. Terry and W. Horton, Phys. Fluids 26, 106 (1983).

11. E. Scime, S. Hokin, N. Mattor, and C. Watts, Phys. Rev. Lett. 68, 2165, (1992).

\section{Appendix A}

\section{Grant-Related Publications and Fusion Program Activities}

Journal Articles or Equivalent (published or submitted, since Sept 15, 1991):

[A.1] G.G. Craddock and P.W. Terry, "Thermally Driven Edge Magnetic Turbulence", Phys. Fluids B 3, 3286 (1991). 
[A.2] D.E. Newman, P.W. Terry, and P.H. Diamond, "Energy Transfer Dynamics of Dissipative Trapped Ion Convective Cell Turbulence", Phys. Fluids B 4, 599 (1992).

[A.3] N. Mattor and P.W. Terry, "Frequency Spectrum in Drift Wave Turbulence", Phys. Fluids B4, 1126 (1992).

[A.4] N. Mattor, P.W. Terry, and S.C. Prager, "Anomalous Ion Heating from the Dynamo in a Reversed Field Pinch", submitted for publication.

[A.5] B.A. Carreras, K. Sidikman, P.H. Diamond, P.W. Terry, and L. Garcia, "Theory of Flow Shear Effects on Long Wavelength Drift Wave Turbulence", submitted for publication.

[A.6] D.E. Newman, P.W. Terry, and P.H. Diamond, "Recent Developments in the Theory and Simulation of Trapped Ion Convective Cell Turbulence", in Transport and Confinement in Toroidal Devices, ed. by C. Alejaldre and B.A. Carreras, (Adam Hilger, Bristol, 1992) p. 127.

[A.7] P.W. Terry and P.H. Diamond, "Basic Concepts of Fully Developed Turbulence", in Transport and Confinement in Toroidal Devices, ed. by C. Alejaldre and B.A. Carreras, (Adam Hilger, Bristol, 1992) p. 15.

\section{Meeting Abstracts or Summaries:}

DPP-APS Annual Meeting, Tampa, FL, November 4-8, 1991.

[A.8] P.H. Diamond, B.A. Carreras, K. Sidikman, L. Garcia, and P.W. Terry, "Drift Wave Turbulence in Rotating Plasmas: A Case Study of Concepts in Shear Suppression of Turbulence" (invited talk).

[A.9] D.E. Newnam, P.W. Terry, and P.H. Diamond, "Effect of ExB and Polarization Drift Nonlinearity on Spectra and Turbulent Transfer in Trapped Ion Turbulence".

[A.10] G. Riggs, D.E. Newman, P.W. Terry, and N. Mattor, "Numerical Study of Frequency Spectra for Drift Wave Turbulence".

[A.11] N. Mattor, P.W. Terry, and S.C. Prager, "Anomalous !on Heating from the MHD Dynamo".

[A.12] F.W. Terry and P.H. Diamond, "Spectrum of Long Wavelength Turbulence in the Presence of Sheared Poloidal Flow".

Fifth Transport Task Force Meeting, Oak Ridge, TN, March 9-12, 1992

[A.13] P.W. Terry, D.E. Newman, and P.H. Diamond, "Studies of a multi-nonlinearity Model of Drift Wave Turbulence" (invited talk). 
[A.14] D.E. Newman, P.W. Terry, and P.H. Diamond, "Computational Modeling of Perturbative Transport in Wavenumber Space".

Sherwood Theory Conference, Santa Fe, NM, April 6-8, 1992

[A.15] P.W. Terry and P.H. Diamond, "Model Studies of L-H Transition Dynamics with Turbulently Generated Differentially Rotating Flow".

[A.16] D.E. Newman, P.W. Terry, and P.H. Diamond, "Computational Study of the Interplay of ExB and Polarization Drift Nonlinearities in Drift Wave Turbulence".

\section{Additional Meetings / Workshops Attended / Talks Given (by P.W. Terry)}

P.W. Terry, "Drift Wave Model of Shear Flow Effects on Turbulence and Confinement", International Conference on New Ideas in Tokamak Confinement, La Jolla, CA, Jan. 27-29. 1992.

N. Mattor, P.W. Terry, and S.C. Prager, "Anomalous Ion Heating from Nonviscous Dynamo Effects", US-Japan Workshop on Anomalous Ion Heating, Madison, March 16-18, 1992.

P.W. Terry, "Shear Flow Effects on the Spectrum of Drift Wave Turbulence", L-H Transition Working Group Meeting, La Jolla, CA, Oct. 10-11, 1991.

P.W. Terry, P.H. Diamond, B.A. Carreras, K. Sidikman, V.E. Lynch, and L. Garcia, "The Physics of Plamsa Turbulence and Nonuniform Flow", Field Task Proposal Nieting, Washington, D.C., March 25-27, 1992.

OFE / DOE Programmatic Activities

Member, Joint Institute for Fusion Theory (JFT) Management Committee.

Member, Sherwood Theory Executive Committee, 1991-1993.

Organizer, US-Japan (JIFT) Workshop on the H Mode and Edge Turbulence, Madison, WI, August 26-29, 1992.

Lecturer, Second Transport Task Force Summer School, Madison, WI, August 19-23, 1992.

Member, Review Panel, DOE Office of Program Assessment Review of Gyrokinetic Simulation, La Jolla, CA, Jan. 21-24, 1992.

Member, IAEA US paper selection committee, Washington, D.C., April 15-16, 1992.

Interim Working Group Leader, Core Fluctuations Working Group, Transport Task Force. 
Member, L-H Transition Working Group, Transport Task Force.

\section{Appendix B}

\section{Grant Modalities}

During the first year of the grant period (Sept. 15, 1991 to Sept. 14, 1992) the participating personnel and their approximate degree of involvement are as follows:
Faculty:
P.W. Terry (Principal Investigator: summer salary, 1992)
Postdocs:
N. Mattor (3 months)
Graduate Students
D.E. Newman (50\% Research Assistant for 12 months)
E. Fernandez (Hourly summer salary, 1992) 

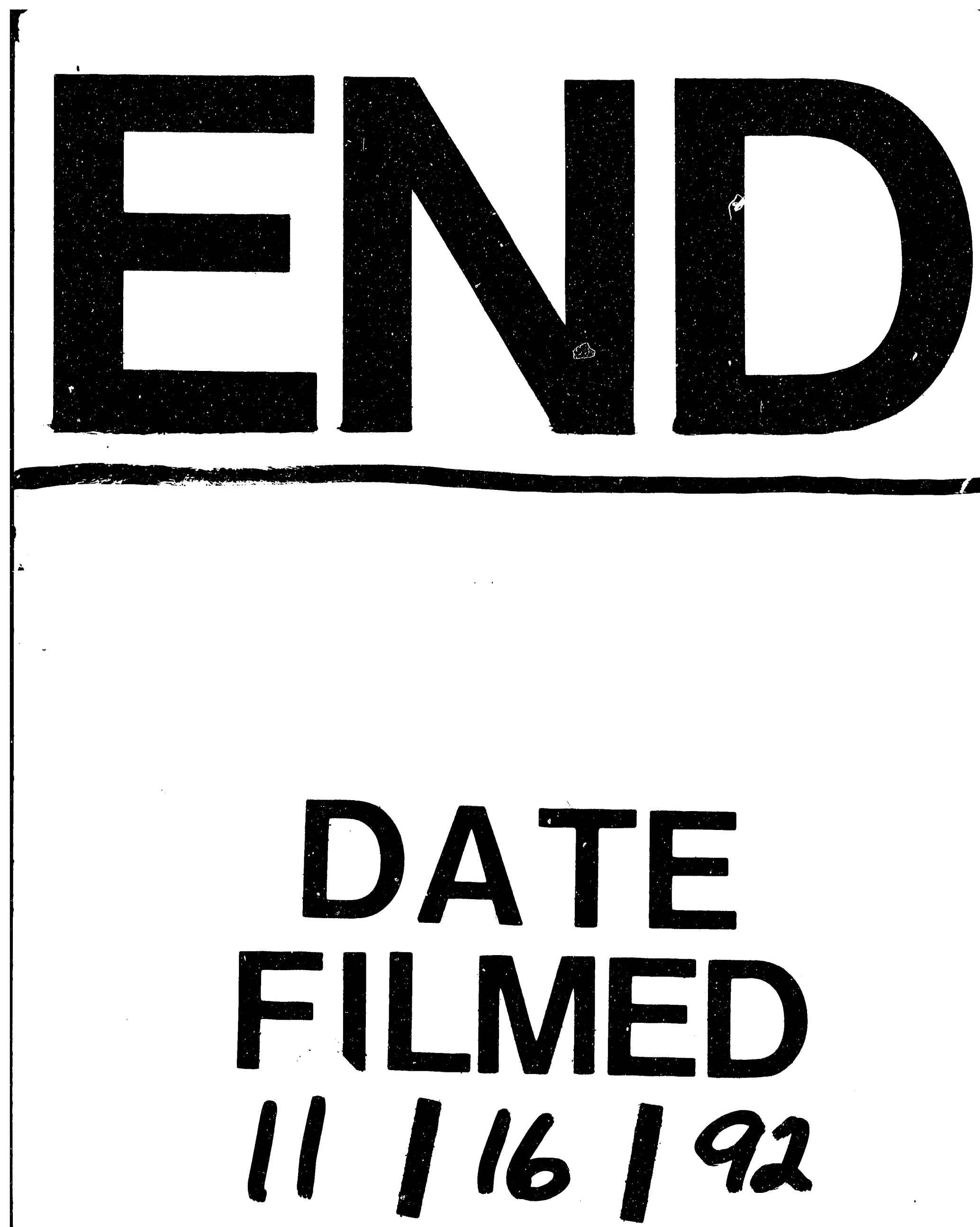
